\section{FACTORS IN THE PROBLEM OF TUBERCULOSIS}

\section{J. MIDDLETON MARTIN, M.D.}

COUNTY MEDICAL OFFICER OF HEALTH, GLOUCESTERSHIRE

In the following numbered paragraphs I have set out what appear to me to be salient facts in the consideration of the problem of tuberculosis, all of which must have due weight in our conclusions for administrative purposes. They could be extended considerably, but those given seem to cover the essential aspects.

1. It is generally accepted that tuberculous infection is almost universal in this and some other countries-for example, 90 per cent. of children under the age of 18 in large towns in Europe and America react to tuberculin tests. ${ }^{1}$ In a study of post-mortem records Vining ${ }^{2}$ showed that 50 per cent. of 563 children between the ages of 5 and 15 had tuberculous lesions, and that in the case of 103 deaths from accidents, 14 (13.5 per cent.) showed such lesions.

2. Between 1838-42 and 1911-15 the pulmonary tuberculosis death rate in England and Wales fell steadily from 3.78 per 1,000 to 1.05 . It has been suggested that the fall has been more rapid since treatment schemes were adopted. In support of this Sir Robert Philip ${ }^{3}$ quoted Birmingham figures (tuberculosis, all forms) showing a "percentage decrease" of 4.15 between $1883-87$ and 1898-1902, and a similar decrease between 1903-7 and 1918-22 of 24.24. This was indicated also by the report of the Registrar-General for 1920. In England and Wales for the years (as nearly as possible) taken by Sir Robert Philip for Birmingham, the figures for the pulmonary tuberculosis death rate are:

\begin{tabular}{cccc|cccc}
$1881-1885$ & $\ldots$ & $\ldots$ & 1.83 & $1901-1905$ & $\ldots$ & $\ldots$ & 1.22 \\
$1896-1900$ & $\ldots$ & $\ldots$ & 1.32 & $1921-1925$ & $\ldots$ & $\ldots$ & 0.86 \\
Fall & $\ldots$ & $\ldots$ & 0.51 & Fall & $\ldots$ & $\ldots$ & 0.36 \\
Decrease & per cent. & 27.8 & 1)ecrease & per cent. & 29.5
\end{tabular}

Had the figure for 1916-20 (1.10) been taken instead of that for 1921-25, the fall for the interval of fifteen years (taken by Sir Robert Philip) would have been only 9.9 per cent.

3. The numbers of persons in Gloucestershire at any given time known to have had illness leading to notification as suffering from tuberculosis are about 2,000 for pulmonary tuberculosis and about 1,000 for nonpulmonary tuberculosis-a total of 3,000 , or about 1 per cent. of the population. This implies that some 99 per cent. of the population have been infected in early years of life, but at no time have presented signs of illness which were attributed to tuberculosis.

4. In some countries illnesses from tuberculosis are exceedingly acute. ${ }^{4}$ For example, in the case of Indians of the Canadian plains tuberculosis was almost epidemic from 1884 to 1904 , and then subsided gradually. Even now the death rate among Indians is about 8 per 1,000 , or nearly twenty times that of the surrounding white population. Ferguson (Saskatchewan) reported that 90 per cent. of school children reacted positively to tuberculin. In French equatorial Africa the primitive races show severe and rapidly progressive forms (Vassal).

5. The incidence of bovine tuberculosis in cattle in this country is indicated by the following figures: 40 per cent. of cows react to tuberculin; and 7 per cent. of milk is tuberculous.

6. Only a small proportion of children can be, or can have been, in close association with known cases of human tuberculosis; yet of 229 bone and joint cases among children under 10 years of age reported by A. Stanley Griffiths, ${ }^{6}$ the organisms in 164 cases (71.6 per cent.) were regarded as due to the human type ; in 59 (25.7 per cent.) as due to the bovine type; and in 6 (2.6 per cent.) as atypical.
7. On the other hand, most children have the opportunity of drinking cow's milk, 7 per cent. of the samples of which are reported to be infected with the bovine form of the bacillus.

8. As children grow older, the proportion of cases of bone and joint tuberculosis attributed to the bovine organism is reported to fall as follows : ${ }^{7}$

$$
\begin{array}{llllllll}
\text { Under } 5 \text { years } & \ldots & \ldots & \ldots & \ldots & \ldots & 32.8 \text { per cent } \\
5 \text { to } 9 \text { years... } & \ldots & \ldots & \ldots & \ldots & \ldots & 24.5 & , \\
10 \text { to } 15 \text { years } & \ldots & \ldots & \ldots & \ldots & \ldots & 12.1 & , \\
16 \text { to } 24 \text { years } & \ldots & \ldots & \ldots & \ldots & \ldots & 10.5 & , \\
25 \text { years and over } \ldots & \ldots & \ldots & \ldots & \ldots & 0 & ,
\end{array}
$$

9. The type of organism reported in cases of pulmonary tuberculosis is almost invariably the human form, but occasionally it is described as the bovine type. Thus B. Lange ${ }^{8}$ reports four such cases; in one the bovine were mixed with human bacilli.

10. To account for the discovery of the human type of organism in pulmonary tuberculosis, the explanation (originating, it is believed, in the United States) put forward is infection later in life by a new bacillus of the human type, though it is more or less generally accepted that immunity, more or less complete, is afforded by early infection. "Massive" doses are regarded as leading to the reinfection. Presumably such "massive" infection could obtain no more effectually than between husband and wife, but there is little evidence of conjugal infection. ${ }^{9}$ In his Lady Priestley Memorial Lecture to the National Health Society on November 29th, 1912, Professor Elie Metchnikoff related his own experience, attributing his immunity to infection from a tuberculous wife to non-pulmonary trouble early in life.

At the age of 23 he married a woman of the same age, who was so ill with pulmonary tuberculosis that she had to be carried in a chair up the few steps leading to the church. She died from tuberculosis four years afterwards. $\mathrm{He}$ " passed the greater part of that time by her side, in the greatest intimacy, without taking any precaution against the contagion." His explanation of his immunity was that he suffered from ophthalmic scrofula when young, and, at the time of speaking, had ganglia in the neck, "very probably of bacillar origin."

11. In view of the facts: $(a)$ that it is rarely that pulmonary tuberculosis occurs in a person with marked evidence of non-pulmonary lesion; $(b)$ that there is little, if any, evidence that even such massive infection as is possible under conjugal conditions produces pulmonary tuberculosis; and $(c)$ that tuberculous infection in early life is almost universal in this country, and illness due thereto is exceptional ; the conclusion would appear to be that pulmonary tuberculosis in later life occurs in members of the population who have not had much active tuberculous infection when young, and in whom marked immunity by such tuberculous infection has not been produced.

12. The explanation, at the present time, of the occurrence of pulmonary tuberculosis in later life is reinfection (see 10), and the necessity for such an explanation appears to be the character of the organism found-mainly the " human" type, as contrasted with the "bovine" type.

13. The distinction between these two main types is based on cultural and virulence characteristics of rather a refined nature. Ordinarily, an organism conforms generally to one or other of the main types, but this is not always the case. For example, Dr. Stanley Griffiths ${ }^{10}$ observes in his note on the second series of 261 cases: "No difficulty was found in classifying the cultures from 251 cases. . . . There remain 10 viruses the cultures from which did not conform exactly either to the human or bovine type." Eight of the ten were designated "dysgonic" human; the remaining two atypical " viruses are more difficult to classify." Finally-for reasons which he sets out-he concludes: " the combination of characteristics . . . justifies in my opinion the classification of these two viruses as 'attenuated bovine." "'

14. This difficulty is further evidenced in the recent investigation of the Lubeck catastrophe, following the use 
of vaccine with the B.C.G. strain, in the course of which it was not found possible to make definite diagnosis of the types of organisms discovered in the material available for examination. In the report of the investigation published in the British Medical Journal ${ }^{11}$ occurs the following sentence:

"There is rapidly growing up a mass of careful observations, made on bacteria of different species, which indicate that the cultural appearances, the antigenic structure, and the virulence of an organism may be altered by a number of different environmental factors, and no one who was not completely ignorant of recent work in the field of bacterial variation would dare to maintain that a given culture was of fixed and immutable virulence."

15. It would seem that very striking evidence in this connexion is given in Dr. A. Stanley Griffiths's findings quoted above in paragraph 13 . In a very large proportion of cases the organism had become the "human" type by the time children reached the age of 5 years. This tendency continued until, when they had reached the age of 25 years, Dr. Griffiths failed to find evidence of the bovine type, though presumably the disease and the cause were the same as at the younger ages. The conclusion may be that the environment does not produce its full results on the organism for almost countless generations.

16. It would appear that, ordinarily, not only is massive infection less common than in the past, but also that the resistance of persons in this country is of so high an order that illness rarely follows infection, and that, even when it does occur, recovery is the rule. If the resistance is overcome later in life it can be increased by special measures and care in the way of healthy living, but not completely. Thus, in something like 50 per cent. of " early" cases death occurs within five years of the patients leaving sanatoriums. In Gloucestershire, of 45 patients in 1923,51 per cent. were dead in 1927. In London, ${ }^{12}$ in $695 \mathrm{~A}$ and $\mathrm{B} 1$ cases, there were 184 deaths (26.4 per cent.); and in 1,871 B 2 cases there were 1,268 deaths $(67.8$ per cent.). It will be seen that in these 2,566 London cases there were 1,452 deaths, the percentage being 56.6.

17. It is not to be concluded that all the administrative measures with respect to tuberculosis of the past sixteen years have been wasted effort. On the contrary, though they have not been so greatly successful in the directions many expected, there has been a stimulus in everything that makes for healthy living, by which the population generally has benefited in a degree that probably would have been obtained in no other way.

\section{Conclusions}

The above brief statements might be considerably enlarged, but those given appear to be sufficient to yield the following conclusions.

The population of this country is almost universally infected in the early years of life (1), and, irrespective of direct action, the incidence of illness and death due to this infection fell steadily in the past century (2). Observable trouble, resulting from childhood infection, is somewhat of the nature of an accidental occurrence in about 1 per cent. of the infected population: tuberculosis of other parts than the lungs in about one-third of the 1 per cent. in the earlier years of life, and tuberculosis of the lungs in about two-thirds of the 1 per cent. in later life (3). The infection is derived mainly from milk (5, 6, and 7), and the characteristics assumed by the organism, while often of the bovine type in the young, are increasingly those of the human type ( 8 and 9$)$. Assuming that the affections of bones and joints are one disease throughout, after the countless generations of organisms which occur in twenty-five years of human life the organism has entirely adopted the characteristics produced by its habitat at the end of twenty-five years (8 and 15).

The infectivity of persons with marked pulmonary tuberculosis can be judged most reliably from the comparatively rare examples of the intimacy of married life, and, so far as evidence goes, affected persons do not infect their partners (10). Tuberculosis schemes do not appear to have had appreciable result in reducing the amount of tuberculous illness ( 2 and 16), but have probably had a direct value in emphasizing the principles of healthy living, thereby reinforcing the general tendency of social betterment of the past century.

The general conclusion would appear to be that, in the circumstances of this country, our aim should be to reduce the infection to the minimal protective dose-for example, by the commercial pasteurization of milkand to persevere in all efforts in the improvement of the conditions of life in all directions.

Referexces
${ }^{1}$ British Medical Journal, January 10th, 1931, p. 63.

2 Itjid., Augtist 30th, 1924, p. 366 .

${ }^{3}$ Address at the Conference of the National Association for the Prevention of Tuberculosis at Birmingham, July, 1923.

4 British Medical Joumal, October 20th, 1928, p. 714

${ }^{5}$ Buckley, Wilfred: Milk and Tuberculosis, Royal Institute of Public Health, May 17th, 1923, p. 8 ; and Bovine Tuberculosis in Man, Report of Ministry of Health, No. 63, p. 9.

${ }^{6}$ Griffiths, A. Staniey: Types of Tubercle Bacillus in Human Bone and Joint Tuberculosis, Joum. Path. and Bact., 1928, xxxi, 879 .

'Ibid., 1928, xxxi, 890

${ }^{8}$ British Medical Journal Supplement, Nay 16th, 1931, p. 94.

${ }^{9}$ Tillisch, Sofie: British Medical Journal Supplement, October 15th, 1921, p. 54; Roussel, P'aul: British Mcdical Joumel, April 7th, 1923, p. 603.

${ }^{10}$ Griffiths, A. Stanley: Loc. cit., p. 877.

${ }^{11}$ British Medical Journai, June 6th, 1931, p. 988.

${ }^{12}$ Ibil., January 31st, 1931, p. 191.

\section{flofia at Hetera}

\section{A MEDIAEVAL POISON GUP MADE FROM THE TERRA SIGILLATA OF MALTA}

In the Mediaeval Department of the British Museum is an object that was formerly described as "The base of a plaster cup used against poison." It is stamped with the image of St. Paul holding a staff around which a serpent is entwined, and is inscribed "Pietra D. S. Paulo. Contra Veleno." Embedded in the base are three small polished stones of a pale orange colour.

The similarity between the representation of St. Paul on this fragment and the stamps used for the terra

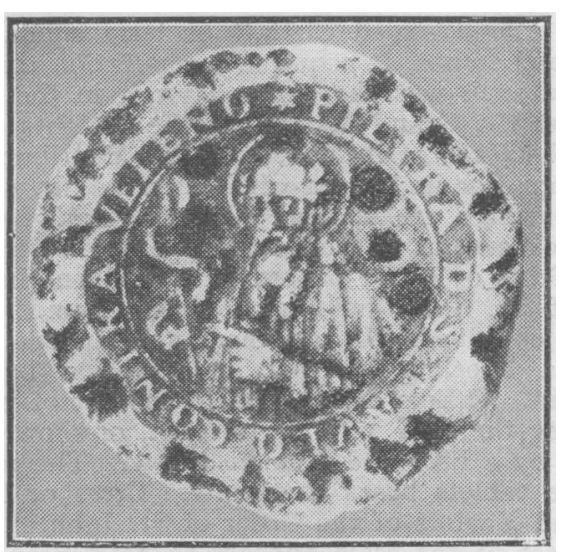

sigillata of Malta led me to make a careful examination of the object. It proved to be the base of a cup, slightly concave on the upper side bearing the stamp, and convex at the bottom, which has a circular flat rim so that it could stand upright. The edges are irregular where the sides have been broken, but otherwise the base of the cup, which measures two and three-quarter inches in diameter, is perfect. The material of which it is composed, 